\title{
RBEP
}

\section{Significados da noção de qualidade da educação na arena educacional brasileira}

Joana Buarque Gusmão

\section{Resumo}

Compartilha resultados de pesquisa pautada pelo seguinte problema de investigação: "O que está em jogo nas noções de qualidade da educação para alguns dos principais atores sociais do campo educacional?" A partir da delineação de uma arena composta por atores sociais situados no Estado, na sociedade civil e em organismos multilaterais, foram realizadas entrevistas semiestruturadas, com seus integrantes, abordando perguntas relativas às razões de a qualidade da educação estar em pauta, à concepção de qualidade e às disputas subjacentes à noção. Concluiu-se que está em jogo nas noções de qualidade da educação a redução das desigualdades educacionais, vista por dois prismas: 1) a elevação do desempenho dos estudantes nas provas de larga escala; e 2) a garantia de condições de ensino que conduzam a uma formação ampla dos estudantes.

Palavras-chaves: qualidade da educação; educação escolar; política educacional. 


\section{Abstract \\ Meanings of quality of education notion in the brazilian educational field}

The article shares some results of research that is guided by the following research problem: what is at stake in notions of quality education for some of the main social actors in the educational field? From the delineation of a ring, composed of social actors within the State, civil society and multilateral organizations, were semistructured interviews with its members, addressing questions on the grounds of the quality of education being at stake, the design quality and disputes underlying the concept. It was concluded that is at stake in the notions of quality of education the reduction of inequalities in education, seen from two angles: 1) increase of student performances on large-scale tests and 2) ensuring a variety of teaching conditions, that would provide students with a broad education.

Keywords: quality of education; school education; educational policies.
${ }^{1}$ A dissertação de mestrado na qual este texto se baseia foi realizada com financiamento da Capes.

\section{Apresentação}

A qualidade tem figurado na pauta das principais instituições que atuam na educação pública no País. Com diferentes graus de ênfase, essas instituições têm incluído a noção em seus posicionamentos, reivindicações, objetivos e propostas de políticas; tudo indica que há um amplo consenso de que a qualidade é o principal "problema" da educação brasileira.

Se o tema é onipresente, nada indica que tenha uma compreensão unívoca. Carvalho (2004) afirma que a expressão "qualidade da educação" seria uma entre tantas outras veiculadas como palavras de ordem ou lemas educacionais, formando discursos vagos e consensos carregados de carga retórica, encerrando divergências conceituais e programáticas.

Nesse sentido, a pesquisa ${ }^{1}$ da qual este artigo resultou se pautou pelo seguinte problema: o que está em jogo nas noções de qualidade da educação para alguns dos principais atores sociais do campo educacional? Para tanto, foi reconstituída uma arena composta por atores relevantes da área educacional brasileira, que fazem parte das disputas acerca da qualidade da educação. Em seguida, adotou-se como estratégia a realização de entrevistas com seus integrantes. Com base num roteiro semiestruturado, foram feitas perguntas relativas às razões de a qualidade da educação estar em pauta, à concepção de qualidade e às disputas subjacentes à noção. Este artigo apresenta alguns dos achados da pesquisa. 


\section{Metodologia}

O delineamento da arena foi apoiado pelos conceitos sistematizados por Rua (1998a, 1998b) para a análise de políticas públicas. Segundo ele, a elaboração de políticas públicas é marcada pelo processamento de um problema político constituído de "demandas que lograram ser incluídas na agenda governamental". As políticas públicas seriam respostas, conjuntos de decisões e ações que se destinam a solucionar os problemas políticos. O processo de configuração de um problema político e seu processamento pelo sistema é conduzido por atores que transitam e interagem no ambiente político, fazendo provocações e apresentando demandas. Rua (1998a, p. 732) define os atores políticos e sociais como "todos aqueles que têm alguma coisa em jogo no tocante a uma questão e que possuem algum tipo de recurso de poder", com alguma capacidade de influência na tomada de decisões e podendo ser por elas afetados.

Os atores políticos se distinguem entre públicos e privados. Os públicos são "aqueles que exercem funções públicas e mobilizam os recursos associados a essas funções" (Rua, 1998b, p. 236). ${ }^{2}$ Os privados não têm vínculo com o aparelho de Estado: são agrupamentos de empresários, igrejas, organizações não governamentais (ONGs), associações civis, entre outros. Rua se refere ainda à importância crescente das agências internacionais no processo político e destaca o papel da mídia por sua capacidade de formar opinião e mobilizar outros atores.

No esforço de explicitação da composição da arena, buscou-se selecionar órgãos públicos e organizações que materializassem a ação desses atores sociais situados no Estado, na sociedade civil e em organismos multilaterais, estabelecendo quem tem alguma coisa em jogo em relação à pauta da qualidade na agenda educacional brasileira. Na sociedade civil, procurou-se incluir organizações representativas de diferentes grupos, buscando assim contemplar interesses, características e pontos de vista distintos: dirigentes educacionais, magistério, estudantes, especialistas/pesquisadores, as chamadas ONGs e o empresariado.

A reconstituição da arena é um constructo; ela não é apresentada como um lugar plenamente configurado, mas utilizada como meio para compreender o que se passa no campo educacional a partir de uma hipótese. Espera-se que ela contribua para examinar as relações entre os atores, investigando se estão se confrontando em relação à noção de qualidade da educação: Eles estão divergindo? Se um ganha, o outro perde?

O processo de escolha dos atores foi guiado pela identificação de órgãos e organizações que fossem representativos dos grupos mencionados, optando por instituições de visibilidade no campo educacional. Os órgãos e organizações que participaram da pesquisa, juntamente com os nomes dos integrantes que concederam as entrevistas e seus respectivos cargos, ${ }^{3}$ foram:
${ }^{2}$ Entre os atores públicos, Rua diferencia duas categorias: os políticos e os burocratas.

${ }^{3}$ Os cargos indicados eram ocupados pelas pessoas no período da realização das entrevistas. Alguns deles já não eram mais preenchidos pelos indicados no momento de finalização da pesquisa. 
- Comissão de Educação e Cultura da Câmara dos Deputados: Maria do Rosário Nunes, presidente;

- Conselho Nacional de Educação (CNE): Antonio César Callegari, presidente da Câmara de Educação Básica;

- Ministério da Educação (MEC): Arlindo Queiroz, diretor de programas da Secretaria-Executiva Adjunta, e Maria do Pilar Lacerda Almeida e Silva, secretária de Educação Básica.

\section{Organismos multilaterais}

- Banco Mundial: Madalena dos Santos, especialista sênior em educação;

- Fundo das Nações Unidas para a Infância (Unicef): Maria de Salete Silva, oficial de educação.

\section{Sociedade civil}

${ }^{4}$ A Undime é uma associação civil que congrega os titulares das secretarias municipais de educação. Carrega, portanto, uma ambiguidade: de um lado, é uma entidade da sociedade civil, de direito privado; de outro, representa gestores públicos.

5 A CNTE também apresenta uma ambiguidade, pois se trata de uma organização sindical (portanto, privada) de atores públicos - na lin guagem de Rua, os "burocratas".

${ }^{6}$ Ainda que o movimento Todos pela Educação tenha uma composição heterogênea, a instituição sobressai pela presença de empresários entre seus sócios fundadores.

${ }^{7}$ Foram ainda convidados para participar da pesquisa a Comissão de Educação, Cultura e Esporte do Senado Federal, o Conselho Nacional de Secretários de Educação (Consed), a Organização das Nações Unidas para a Educação, Ciência e a Cultura (Unesco) e a União Brasileira dos Estudantes Secundaristas (Ubes). Com a Ubes, não conseguimos contato. Foram enviados e-mails para endereços disponíveis no site da entidade e todos voltaram. Tentamos também contatos telefônicos em dias e horários variados, mas as ligações não foram atendidas. Já os representantes do Consed, da Unesco e da Comissão de Educação do Senado manifestaram interesse em participar da pesquisa, contudo, não foi possível viabilizar agenda.
Dirigentes educacionais:

- União Nacional dos Dirigentes Municipais de Educação (Undime) ${ }^{4}$ - Carlos Eduardo Sanches, presidente.

Magistério:

- Confederação Nacional dos Trabalhadores em Educação (CNTE) Roberto Franklin de Leão, presidente.

Especialistas/ pesquisadores:

- Associação Nacional de Pós-Graduação e Pesquisa em Educação (ANPEd): Sandra Maria Zákia Lian Sousa, vice-presidente.

ONGs:

- Campanha Nacional pelo Direito à Educação: Daniel Cara, coordenador geral;

- Instituto Ayrton Senna: Tatiana Filgueiras, coordenadora da Área de Avaliação e Desenvolvimento.

Empresariado:

- Todos pela Educação6: Maria Lucia Meirelles Reis, diretora administrativa, e Priscila Fonseca da Cruz, diretora executiva.

Ao todo, foram entrevistadas 13 pessoas em 12 entrevistas (a entrevista do Todos pela Educação foi concedida em dupla), englobando 11 órgãos ou organizações. ${ }^{7}$ Os depoimentos foram concedidos presencialmente nas cidades de São Paulo e Brasília, entre maio e julho de 2009, com duração média 40 minutos. As entrevistas foram gravadas em áudio e transcritas pela pesquisadora responsável. 


\section{Qualidade da educação como uma noção central na agenda educacional brasileira}

- $\mathrm{O}$ (a) senhor(a) considera que a qualidade da educação é um tema central na agenda educacional brasileira das últimas décadas? Se sim, por quê? No que o(a) senhor(a) acha que consiste a vigência da qualidade da educação como um tema tão presente nos discursos e programas de ação no Brasil?

- O(a) senhor(a) / sua instituição / órgão considera a melhoria da qualidade da educação como um desafio nacional no Brasil hoje? Se sim, no que consiste esse desafio?

\section{Concepção de qualidade da educação}

- Quais são os aspectos/ dimensões/ elementos mais importantes que o(a) senhor(a) considera na noção de qualidade da educação?

- Como a questão da aprendizagem se situa na sua visão sobre qualidade da educação? Para o(a) senhor(a), no que consistiria a diretriz de "concentrar a atenção na aprendizagem" como principal aspecto da noção de qualidade da educação?

- Como o(a) senhor(a) avalia o uso dos resultados das provas de larga escala como principal medida de qualidade? Quais são as implicações?

\section{Agenda político-operacional}

- Como sua visão de qualidade se opera programática e politicamente?

- Como sua instituição / órgão tem se inserido nas discussões que tocam a questão da melhoria da qualidade da educação no país? Qual é o programa de ação de sua instituição / órgão no que toca o tema da qualidade da educação?

\section{Campo de disputas}

- Em sua opinião, quais são os principais consensos no Brasil sobre o que é qualidade da educação? E os principais dissensos? Quais seriam as principais divergências conceituais e programáticas? No que consistiria uma disputa em relação à noção de qualidade da educação no Brasil hoje?

- Quem atua a favor de sua concepção de qualidade da educação? Quem atua contra?

- Que crítica o(a) senhor(a) faria às outras concepções de qualidade da educação vigentes na sociedade? Quais são suas maiores fragilidades? 
Tendo Rua (1998b) como referência, a análise dos depoimentos concedidos teve como objetivo a identificação de issues. Segundo ela, o processamento de um problema político pelo sistema é marcado pelo confronto entre os atores políticos ou sociais, que agem segundo suas preferências e interesses. As preferências são resultados de cálculos de custo/benefício de cada uma das alternativas propostas para solucionar um problema. Rua (1998b, p.241) utiliza o termo issue para se referir às preferências dos atores: "item ou aspecto de uma decisão que afeta os interesses de vários atores e que, por esse motivo, mobiliza suas expectativas quanto aos resultados da política e catalisa o conflito entre eles". Em torno das decisões tomadas em cada um dos issues, os atores ganham ou perdem segundo seus interesses e a política assume suas configurações. O trabalho de interpretação foi identificar os issues relacionados à temática da qualidade da educação, identificando as preferências dos atores em relação a eles.

Segundo Rua (1998b, p. 241), "em função das preferências e das expectativas de resultados - vantagens e desvantagens - de cada alternativa na solução de um problema, os atores fazem alianças entre si e entram em disputa" (1998b, p. 241), e formam-se as arenas políticas, que podem ser distinguidas entre distributivas, regulatórias e redistributivas.

As arenas distributivas são aquelas que mobilizam reduzido potencial de conflito, já que tratam, basicamente, da alocação de recursos, distribuição de benefícios, sem que haja clareza sobre quem paga os custos ou perde algo com as decisões. As arenas regulatórias estabelecem imperativos seletivos, quem pode ou não pode ter ou fazer alguma coisa, quem paga o que em determinadas situações, etc. Logo, desencadeiam reações variáveis de adesão ou rejeição. Já as arenas redistributivas são por definição altamente conflituosas, pois, para que certos benefícios sejam alocados, atores e interesses claramente definidos terão de arcar com perdas. (Rua, 1998b, p. 241-242).

Três padrões regem a dinâmica das relações entre os atores: lutas, jogos e debates.

As lutas acontecem, geralmente, quando se trata de arenas redistributivas, nas quais se tem o chamado "jogo da soma-zero", ou seja, uma situação na qual, para que um ator ganhe, o outro perde. [...] Os jogos são situações em que a lógica é vencer o adversário em uma situação específica, sem eliminá-lo totalmente do processo, de tal maneira que ele possa vir a ser um aliado, em um momento posterior. [...] Finalmente, os debates são situações em que cada um dos atores procura convencer o outro da conveniência de suas propostas, de tal maneira que o que vence é aquele que se mostra capaz de transformar o adversário em um aliado. (Rua, 1998b, p. 241-242).

A interpretação dos dados colhidos nas entrevistas permitiu identificar três principais issues ou questões nas quais se formam as preferências dos atores: 1) a concepção de qualidade da educação; 2) o lugar das provas em larga escala; 3 ) as prioridades para as políticas do magistério. Sua análise trará elementos para o tipo de arena formada e a dinâmica das relações estabelecidas entre os atores. 


\section{Concepção de qualidade da educação}

Nos depoimentos acerca das concepções de qualidade da educação, a oposição se deu entre os atores que concebem a "aprendizagem" (entendida primordialmente por meio dos resultados das provas em larga escala) como o principal significado de qualidade da educação e os que defendem uma visão abrangente, com o foco estendido aos processos, às condições gerais de ensino e o aprendizado em uma perspectiva mais ampla que o aferido pelas provas.

A demarcação de dois grupos segundo as ênfases apresentadas é convergente, respectivamente, com o que é denominado, de um lado, rendimento e, de outro, insumos e processos - duas das principais maneiras de se referir à qualidade da educação, segundo Adams (1993).

\section{A ênfase na "aprendizagem" (especialmente a medida pelas provas)}

No primeiro grupo, composto por representantes do Banco Mundial, do MEC, do Instituto Ayrton Senna, do movimento Todos pela Educação, da Undime e do Unicef, a "aprendizagem" é vista como a principal finalidade da escola, sua razão de existir. As concepções por eles desenvolvidas tendem a ser mais substantivas: qualidade é aprendizagem, qualidade é garantir acesso e permanência. Apesar de mencionar a existência de outros aspectos importantes, esses estão condicionados hierarquicamente à aprendizagem, sendo "facilitadores" para sua garantia; ou seja, as "condições" não são importantes a priori, e sim quando estão orientadas para a promoção da "aprendizagem".

Boa parte dos atores desse grupo se referiu também ao acesso e à permanência, que, juntamente com a aprendizagem, formariam o tripé da qualidade da educação. A qualidade, entendida como aprendizagem/ rendimento escolar, teria como condição o acesso e a permanência. Essa visão se relaciona com os depoimentos que consideram que a questão da qualidade vem em substituição à pauta da universalização do acesso à escola e frisaram que "qualidade para poucos não é qualidade". Os esforços se centrariam em garantir que os estudantes permaneçam na escola e em proporcionar o que se espera da escolarização: a aprendizagem, especialmente a medida pelas provas de larga escala. Nota-se que acesso, permanência e rendimento escolar são os indicadores educacionais habitualmente usados pelas políticas públicas.

O depoimento de Carlos Eduardo Sanches, da Undime, foi um dos que tomaram essa direção: "Qualidade da educação significa dar a oportunidade de a criança ir à escola e aprender", disse. Sanches falou também sobre a importância de a escola não ser excludente, garantindo condições de acesso, permanência e aprendizagem para todos.

Maria do Pilar Lacerda, quando inquirida sobre qual seria o principal elemento da noção de qualidade da educação defendida pelo MEC, 
destacou a aprendizagem associada ao acesso e à permanência. Disse ela: "Aprendizagem é o aspecto principal, mas têm outros que andam juntos: o acesso e a permanência. Só garantimos aprendizagem se garantimos o acesso à escola e o fim da evasão escolar."

A aprendizagem foi tomada ainda como a principal dimensão da qualidade por Maria de Salete Silva, do Unicef: "A educação de qualidade é aquela que garante desde o acesso até a conclusão com aprendizagem." Silva comentou os resultados encontrados em estudos realizados pelo Unicef sobre escolas e redes de ensino com bons desempenhos na Prova Brasil e no Sistema Nacional de Avaliação da Educação Básica (Saeb). Entre os vários elementos comuns encontrados, destacou o foco na aprendizagem: "As redes e as escolas estão voltadas para garantir o direito de aprendizagem do menino."

Entre os depoimentos deste primeiro grupo, a compreensão de aprendizagem assumiu um caráter cognitivista, de aquisição e desenvolvimento de conhecimentos, sobretudo os disciplinares, de forma que o desempenho dos estudantes nos testes padronizados foi apontado como o principal indicador de aprendizagem e, consequentemente, de qualidade. Presume-se que o ensino eficiente dos conteúdos prescritos pelas provas resulta num bom desempenho nos testes, o que significaria que a aprendizagem ocorreu e culminou numa melhora da qualidade da educação. Para os representantes da Undime, do Unicef e do MEC, a associação entre aprendizagem e resultados das provas de larga escala não foi tão imediata, ficando mais evidente no decorrer da apresentação dos depoimentos. Já para as representantes do Todos pela Educação, do Banco Mundial e do Instituto Ayrton Senna essa compreensão foi mais explícita: o rendimento escolar seria entendido como o que se espera da escola, o que deve ser garantido a todos. É uma posição que se relaciona com uma visão de resultados: todos os processos escolares devem estar orientados para a garantia de bons resultados de desempenho.

Para Priscila Cruz, do Todos pela Educação, a importância da aprendizagem é o maior consenso existente no que diz respeito à qualidade da educação. Cruz se referiu à concepção de qualidade de sua organização como os resultados de aprendizagem dos alunos medidos pelas provas nacionais de larga escala: "Consideramos a qualidade de uma forma bem pragmática. Para a gente, qualidade é o aluno aprender, é o resultado do aluno, e hoje, com Saeb, Prova Brasil, Enem, Pisa, podemos aferir como está a aprendizagem."

Madalena dos Santos referiu-se à aprendizagem medida pelos testes em larga escala para falar da concepção de qualidade da educação do Banco Mundial. "[Qualidade] é como os alunos estão aprendendo e se estão aprendendo, o que é comprovado por determinados testes e índices que dizem se a qualidade é boa ou ruim."

A aprendizagem dos alunos, especialmente a medida por indicadores como o Saeb, também foi apresentada como primordial na noção de qualidade da educação do Instituto Ayrton Senna por Tatiana Filgueiras: "Para nós, esse conceito de qualidade é uma coisa objetiva, com indicadores 
numéricos que nos sinalizam o quanto a escola pública ganhou em termos de qualidade. [...] O aspecto qualitativo da educação é o aprendizado." Para Filgueiras, a adoção de um conceito objetivo de qualidade da educação, traduzido em indicadores mensuráveis, é fundamental para a execução de políticas públicas.

Tal como apontado por Torres (2001), a aprendizagem aparece como um tema amplamente mencionado, mas ainda muito escorregadio. Apesar de afirmarem a centralidade da aprendizagem, apontando-a como principal finalidade do processo educacional, referem-se a ela como os resultados das provas em larga escala. A diretriz da Conferência de Educação para Todos, "concentrar a atenção na aprendizagem", é traduzida como "melhorar e avaliar o rendimento escolar". Essa simplificação pode ocorrer como uma opção política, pela sua exequibilidade em compor indicadores nacionais. Mas isso não justifica o tratamento da aprendizagem e dos resultados das provas como sinônimos, como aparece em alguns depoimentos. Parece haver uma priorização dos "conteúdos" medidos pelos testes, considerados como fundamentais na escolarização dos estudantes, e um julgamento de que as demais "aprendizagens" proporcionadas pela escola (como a da cidadania, por exemplo) estão em segundo plano, ou, ainda, de que as primeiras seriam condições que levariam à segunda.

\section{Foco estendido aos processos, às condições gerais de ensino e à aprendizagem numa perspectiva ampla}

O segundo grupo de depoimentos, composto por representantes da ANPEd, da Campanha Nacional pelo Direito à Educação, do CNE, da CNTE, da Comissão de Educação e Cultura da Câmara dos Deputados e do MEC, reconhece a importância da aprendizagem, assim como das avaliações centralizadas, mas em suas formulações prioriza uma noção de qualidade da educação mais ampla, isto é, com recorrência a um conjunto de aspectos. Eles se referem à importância de considerar os processos, as condições necessárias para uma educação de qualidade e outros elementos de aprendizagem para além dos conteúdos disciplinares, como a cidadania e a ética. Diferentemente de uma definição substantiva, tal como dada nos depoimentos do grupo anterior, como "qualidade é isto ou aquilo", os depoimentos enfatizam as condições diversas que são necessárias à promoção da qualidade. A qualidade implica e requer condições, tais como infraestrutura, tempos e espaços para desenvolvimento do processo educativo. Destaca-se também a referência do grupo aos valores, à diversidade, à contextualização do ensino e aprendizagem, à participação e à democracia.

Defender a posição de que a educação de qualidade seja orientada para a garantia do direito das crianças e adolescentes à aprendizagem não é o ponto que opõe os atores. O caráter cognitivista e a valorização do resultado das provas em larga escala como os principais significados de 
aprendizagem e, consequentemente, de qualidade da educação aparecem como elementos demarcadores da divergência. Os entrevistados deste grupo se posicionam contra a tendência de reduzir a noção de qualidade a uma dimensão, notadamente a centrada nos desempenhos nas avaliações em larga escala. Dessa forma, frisam a relevância de compreender a qualidade da educação de forma mais profunda. A opção por respostas mais amplas tem, em geral, os objetivos de ressaltar que outros aspectos são relevantes além de um bom desempenho nos testes padronizados ou mesmo dos conteúdos disciplinares, como a [aprendizagem] da ética e da cidadania e a vinculação dos processos e das condições à qualidade da educação.

Arlindo Queiroz, do MEC, ponderou que, ainda que a discussão do conceito de qualidade precise ser aprofundada no País, já se tem avançado na consideração de um conjunto de componentes para além da promoção de bons resultados nos testes, como a contextualização da avaliação e do processo de ensino e aprendizagem, a participação e a diversidade.

Maria do Rosário Nunes, presidente da Comissão de Educação e Cultura da Câmara dos Deputados, defendeu uma visão de qualidade que integre um conjunto de fatores, como a aprendizagem de conteúdos, a participação, a não discriminação e a felicidade. Segundo ela, a diretriz de concentrar a atenção na aprendizagem como o principal aspecto da noção de qualidade da educação "poderia significar um apagamento do processo educativo como um todo, porque a aprendizagem é fruto de um complexo sistema".

Para Sandra Zákia, a questão da qualidade tem assumido vários significados ao longo da história, estando atualmente ligada à formação que vem sendo possibilitada aos estudantes. A vice-presidente da ANPEd ressalta com veemência que "a qualidade tem que ser propiciada a partir de garantia de condições para construção de um trabalho coletivo no interior da escola; é condição a existência de tempo e espaço adequados". Entre os aspectos a serem considerados na noção de qualidade, Zákia ressaltou:

\footnotetext{
Infraestrutura, equipamentos, materiais, dimensões objetivas de desenvolvimento do trabalho. Tem uma dimensão que é o próprio clima das instituições escolares. São as relações de poder, as interações, as dinâmicas, os espaços de interação que propiciam a construção de um trabalho que seja de fato coletivo.
}

Falou ainda da importância da mobilização "em torno de um projeto pedagógico da escola, que não se viabiliza, de fato, se não houver um tempo de convivência, de construção, de negociação, de debate".

Dois dos entrevistados (Daniel Cara e Roberto Leão) empregaram o termo "qualidade social" para revestir suas concepções de qualidade da educação. A abordagem remete à formação que se pretende propiciar aos alunos, tirando o foco unicamente da aprendizagem dos "conteúdos" avaliados pelas testagens e envolvendo o desenvolvimento da ética e a construção da cidadania. "Qualidade social" tem sido um termo 
empregado, tal como apontado por Campos (2006), para marcar uma diferença de posições. Subentende-se a existência de uma concepção de qualidade que não se atenha a valores "sociais", isto é, que dê primazia à dimensão econômica.

Daniel Cara, da Campanha Nacional pelo Direito à Educação, frisou que haveria duas correntes principais na construção da noção de qualidade da educação, uma mais "instrumental", focada na proficiência dos estudantes no tocante, principalmente, a Português e Matemática, e outra mais "social", que "opta por envolver também capacidades éticas, além da aprendizagem do conhecimento formal". Segundo ele, "a Campanha opta por essa segunda noção sem negar a necessidade da proficiência em Português e Matemática, mas também incluindo, obviamente, além da questão da aprendizagem dos valores, as outras disciplinas".

Ao discorrer sobre os aspectos ou dimensões mais importantes na noção de qualidade da educação, Roberto Leão falou sobre a concepção da CNTE de "qualidade socialmente referenciada", em suas palavras, "uma qualidade que leve em conta o desenvolvimento pleno, a construção da cidadania, uma qualidade para a vida, para a pessoa poder intervir na sociedade e alterar sua história. Uma qualidade que atenda aos interesses da maioria da população". Leão falou também sobre a ligação da questão da qualidade com as condições de trabalho e valorização dos profissionais da educação, juntamente com as condições de vida dos estudantes: "A qualidade está diretamente ligada às condições de trabalho, à valorização do profissional, às condições em que o aluno vai para a escola, às condições de vida do próprio aluno." Para ele, o foco na aprendizagem só se justifica se incluir também a cidadania.

A referência à existência de duas dimensões que estariam articuladas na noção de qualidade da educação, uma de natureza cognitiva (aquisição de conhecimentos) e outra de natureza formativa (desenvolvimento de habilidades e potencialidades), esteve presente na fala de César Callegari, do Conselho Nacional de Educação. Ele completou dizendo que "a educação não pode ser só propriamente escolar e se restringir à questão do ensino e da aprendizagem. A educação é um processo muito mais amplo".

\section{Lugar das avaliações em larga escala na promoção da qualidade da educação}

O lugar que as avaliações em larga escala têm no debate sobre a qualidade da educação e nas políticas educacionais é uma questão central no que está em jogo na arena. Apesar da importância da avaliação centralizada poder ser considerada um consenso, os atores divergem na atribuição de seus papéis. Uma parte dos depoimentos tendeu a ressaltar os aspectos positivos do uso das provas e índices como indicadores de qualidade da educação e como eixos estruturantes de políticas e práticas calcadas na busca da qualidade. Outra parte enfatizou com veemência as limitações e distorções no uso dos resultados das provas e dos índices 
tanto como indicadores de qualidade quanto para balizar ações de promoção da qualidade. Entre os pontos que opõem os atores no que concerne ao assunto tratado neste tópico, podemos identificar quatro: 1) reconhecimento dos resultados dos testes e índices correlatos como indicadores de qualidade da educação; 2) capacidade das provas de garantirem o direito à aprendizagem; 3) capacidade das provas e índices nelas baseados de se constituírem como instrumentos de gestão de políticas públicas; 4) capacidade das provas de interferirem no currículo.

A apresentação dos depoimentos organizados em torno dos itens acima será precedida dos trechos das entrevistas que indicam o reconhecimento da importância da avaliação em larga escala na arena.

\section{Importância da avaliação em larga escala}

Nenhum dos atores negou a relevância da avaliação em larga escala - todos foram claros em reconhecê-la. Nesse entendimento, três visões predominaram nos depoimentos: há os que compreendem que as testagens e os índices nas quais estão baseados são consensuais no País, ainda que haja discordâncias acerca de seus limites; há os que se referem às provas e aos índices como questões que não têm sido alvo de grandes polêmicas ou controvérsias, mas não são taxativos em afirmar que se trata de um consenso; e, por fim, há um subgrupo que afirma haver setores contrários à existência das avaliações padronizadas, sem, entretanto, especificar quais setores seriam - se de fato existem, são atores que não fazem parte da arena reconstituída para a pesquisa na qual este artigo se referencia.

Para Arlindo Queiroz, o Índice de Desenvolvimento da Educação Básica (Ideb) - indicador nacional baseado nos resultados das provas em larga escala e nas taxas de aprovação - seria um consenso: "O Ideb, que é um instrumento consensual, inclui indicadores de fluxo escolar e de desempenho escolar a partir de uma avaliação externa que hoje é consensual - o País todo aceita essa questão."

Para Maria de Salete Silva, a importância da avaliação de aprendizagem, que estaria alcançando um novo lugar no processo educacional, mais central, seria um consenso no País. Um indício para a existência desse consenso seria que o Unicef não tem encontrado resistências em relação a processos de avaliação de aprendizagem. Segundo Silva, o organismo internacional não tem recebido nenhum tipo de crítica às pesquisas realizadas com base nos resultados dos testes em larga escala.

Carlos Eduardo Sanches, presidente da Undime, reconheceu que a medição dos resultados de aprendizagem dos estudantes já não encontra tantas resistências no País, como num passado recente. No entanto, quando indagado diretamente se a avaliação por larga escala seria um consenso no País, Sanches fez uma ressalva: "Não é um consenso, há um entendimento, mas algumas pessoas ainda criticam." 
Sandra Zákia, da ANPEd, afirmou: "Sem dúvida, a avaliação em larga escala tem uma função muito importante. O que acho é que se está atribuindo um peso em relação à avaliação em larga escala como se ela fosse a panaceia de todos os males." Roberto Leão, da CNTE, referiu-se ao Ideb como um indicador que se mostra limitado ao não considerar variáveis importantes, não podendo ser considerado um indicativo de qualidade da educação, porém não afirmou que as provas e o Ideb não tenham relevância ou devam ser totalmente desconsiderados.

Daniel Cara, da Campanha Nacional pelo Direito à Educação, afirmou que existem pessoas que negam a importância das avaliações em larga escala, posição da qual ele diverge: "Analisando friamente, a proficiência em Português e Matemática não é o maior consenso, em minha opinião. Acho que tem gente que erroneamente tende a negar a importância dela. É um critério avaliativo incompleto, mas importante."

A presidente da Comissão de Educação e Cultura da Câmara dos Deputados, Maria do Rosário Nunes, posicionou-se alinhada a setores da sociedade que são a favor das avaliações em larga escala, mas que se situam dentro de uma perspectiva mais ampla, não afeita a classificações. Para a deputada, alguns setores da sociedade se colocam totalmente contrários à avaliação externa: "Permanece existindo um setor absolutamente contrário a qualquer avaliação externa da escola. [...] Um setor politicamente situado dentro do Congresso Nacional, nas instituições, no meio educacional."

\section{Resultados dos testes e índices correlatos como indicadores de qualidade da educação?}

Se todos convergem em aceitar a importância das provas em larga escala, divergem na atribuição de seus papéis. Nesse sentido, uma das principais discordâncias entre os atores é acerca do reconhecimento dos resultados dos testes e índices correlatos como indicadores de qualidade da educação. Três visões principais foram identificadas: a primeira, destacando a valorização do caráter objetivo das testagens e do Ideb, concebe-os como instrumentos inequívocos de avaliação da aprendizagem e da qualidade da educação; a segunda reconhece sua legitimidade como indicadores de qualidade, porém também reconhece seus limites; para a terceira, os testes e índices desconsideram aspectos e fatores fundamentais do processo educativo, especialmente os ligados aos processos e às condições de vida dos alunos e de trabalho dos professores, questionando, assim, os limites da avaliação proporcionada.

No primeiro grupo encontram-se os depoimentos dos representantes do Banco Mundial, do Instituto Ayrton Senna, do Todos pela Educação e da Undime. Para Madalena dos Santos, do Banco Mundial, o Ideb permite mensurar a qualidade. Disse ela: "O Ideb foi o ovo de Colombo, todo mundo sabe onde é que está, como é que está. A definição de indicadores possibilita definir uma qualidade." 
O presidente da Undime, Carlos Eduardo Sanches, se referiu às provas como um mecanismo de avaliação, um meio de verificação da aprendizagem dos estudantes: "A aplicação das provas vai nos garantir a possibilidade de construir um modelo adequado. Porque é direito da criança aprender. E qual outro mecanismo que temos para avaliar isso hoje?" - questionou.

Para Tatiana Filgueiras, do Instituto Ayrton Senna, idem: "O conceito de qualidade é uma coisa objetiva, com indicadores numéricos que nos sinalizam o quanto a escola pública ganhou em termos de qualidade. [...] é preciso avaliar dentro de um padrão comparativo que seja conhecido" - no caso, o Saeb.

Os indicadores nacionais do Saeb e da Prova Brasil são a principal medida de qualidade para o Todos pela Educação, segundo Priscila Cruz: "Qualidade é o aluno aprender, é o resultado do aluno, e hoje, com Saeb, Prova Brasil, Enem, Pisa, podemos aferir como está a aprendizagem."

Entre os que defenderam os resultados das provas e índices nela baseados como indicadores de qualidade da educação, ainda que reconhecendo seus limites, estão os representantes do MEC e do Unicef.

Maria do Pilar Lacerda, do MEC, considerou que o Ideb "não é a única medida, mas é uma importante medida, que, nacionalmente, é possível de ser feita". Ela reconhece que o Ideb não é capaz de identificar alguns aspectos importantes, entretanto isso não desqualifica o índice, que seria complementado com a realização de estudos de práticas exemplares.

Para Maria de Salete Silva, "o Ideb deu uma enorme contribuição para levar a discussão da qualidade da educação para onde ela deveria ir, que é a aprendizagem dos meninos". E acrescenta: "Não quero dizer que o Ideb seja 'o' indicador de qualidade da educação, ele não é." As discussões em torno da possibilidade de existência de indicadores nacionais foram por ela levantadas: "Se é possível ou não ter indicadores nacionais, essa é uma discussão, não sei nem se podemos dizer que é uma divergência." Para a representante do Unicef, a contextualização da educação diante da existência de padrões nacionais seria uma divergência: "A área que tem maior questionamento é quando se discute contextualização da educação. Por exemplo: material didático, conteúdo de prova. Pode haver uma prova do Oiapoque ao Chuí?"

Entre os que apontaram com maior intensidade os limites dos testes e índices estão os representantes da ANPEd, da Campanha Nacional pelo Direito à Educação e da CNTE. Sandra Zákia falou sobre a legitimação dos testes e sua assimilação como expressão da qualidade da educação: "As provas, para a sociedade como um todo, conseguiram uma legitimação. [...] Leem esses resultados como indicação de qualidade. No entanto, é uma limitação na forma de ver, de conceber qualidade da escola." Para a vice-presidente da ANPEd, uma decorrência da ênfase nas testagens em larga escala como uma expressão da qualidade do ensino seria a redução da avaliação a uma ideia de verificação, de medida e de aplicação de prova, o que estaria fortalecendo a dimensão de resultados em prejuízo da dimensão de processos, reconhecida por ela como parte importante 
na noção de qualidade da educação. Zákia realçou como desafio para as políticas educacionais a ampliação das sistemáticas de avaliação para a inclusão de dimensões de processo: "Esse é um desafio que se coloca: como criar instrumentos, procedimentos, processos, sistemáticas que apreendam, se não toda a complexidade do processo educativo, ao menos um pouco mais de sua dinâmica, de organização, de desenvolvimento do trabalho."

Para Daniel Cara, conceber as provas e o Ideb como indicadores da qualidade da educação é reduzir a noção a um conceito de proficiência, excluindo fatores importantes para o alcance da qualidade na educação. Segundo o coordenador da Campanha Nacional pelo Direito à Educação, esse modelo de avaliação é frágil, pois se baseia somente nas "respostas dos alunos" para fazer inferências sobre todo o sistema, não oferecendo indicações de melhoria. Cara defende a ampliação da política de avaliação com a inclusão de novas variáveis. Disse ele: "Acredito que é preciso fazer esse tipo de avaliação, mas é preciso incluir variáveis, como no ensino superior, de infraestrutura, de qualificação dos professores, número de alunos por sala de aula, etc.; este é o desafio que a Campanha quer enfrentar, como fez com o Custo Aluno-Qualidade Inicial".

O presidente da CNTE, Roberto Leão, opinou que as provas não podem ser consideradas indicadores de qualidade da educação, pois apresentam potencial reduzido de captação de variáveis como as condições de trabalho, a valorização dos profissionais da educação e as condições de vida dos alunos, questões diretamente ligadas à qualidade: "Essas são variáveis que fazendo um simples teste você não consegue pegar. As provas, por si, não conseguem servir de indicadores da qualidade na educação" - ponderou.

Para a deputada Maria do Rosário Nunes, as provas em larga escala são importantes, mas não devem ser analisadas isoladamente, podendo levar a distorções. Ela defendeu a realização de estudos de fatores associados aos resultados dos testes.

Arlindo Queiroz, do MEC, ponderou que os limites da avaliação baseada nas provas de larga escala são objetos de divergência, especialmente entre os que consideram que outros elementos devem ser levados em conta na noção de qualidade da educação, além dos resultados dos testes e do fluxo, como questões ligadas à contextualização e às condições educacionais e sociais.

\section{Capacidade de as provas garantirem o direito à aprendizagem?}

Outra capacidade atribuída às provas em larga escala é a de assegurar ao estudante a garantia do direito de aprender o que seria esperado; as provas diagnosticariam uma situação e seriam parte da solução dos problemas identificados. Nesse sentido, os depoimentos abarcam os testes e o Ideb como parte fundamental das políticas destinadas à geração de qualidade/promoção da aprendizagem. Os integrantes do Instituto Ayrton 
Senna, da Undime e do Unicef manifestaram esse entendimento, já a da ANPEd se posicionou de forma contrária.

Carlos Eduardo Sanches se referiu às provas de larga escala como um instrumento fundamental na promoção do direito de aprender dos alunos. Para o presidente da Undime, a avaliação centralizada traz informações essenciais aos professores na organização de seu cotidiano na sala de aula, possibilitando um comprometimento com a aprendizagem de cada criança, individualmente.

Para Tatiana Filgueiras, do Instituto Ayrton Senna, as provas de larga escala refletem a base de aprendizagem que possibilitará às crianças e adolescentes continuarem aprendendo ao longo da vida. Disse ela: "O pavimento da estrada para que o menino alcance tudo isso, que é a felicidade, que é a qualidade de vida, é o acesso à oportunidade educativa mensurável."

Para Maria de Salete Silva, os estudos realizados pelo Unicef mostram que o resultado das avaliações nacionais faz as redes se mobilizarem para garantir o direito à aprendizagem, contribuindo para uma mudança nas práticas das escolas, focando seu trabalho no que é prioritário. As testagens e o Ideb estariam colaborando para a construção de outros significados e práticas para a avaliação. "O Ideb deu uma enorme contribuição para levar a discussão da qualidade da educação para onde ela deveria ir, que é a aprendizagem dos meninos" - completou.

Já para Sandra Zákia, a avaliação em larga escala no Brasil não tem tido o poder de trazer para o debate nacional a questão da aprendizagem como elemento central do processo educativo. A vice-presidente da ANPEd também não considerou que as avaliações tenham possibilitado a reorganização dos processos e práticas educativas em torno da aprendizagem. A razão principal, segundo ela, seria o princípio equivocado que rege a avaliação, que entende que o controle e a responsabilização são determinantes para fazer os agentes educativos corrigirem suas práticas e melhorarem seu desempenho. Disse que "a mera intensificação de controle, sem criar as condições efetivas de aprendizagem, acaba não cumprindo esse objetivo".

\section{Provas e índices nelas baseados como instrumentos de gestão de políticas públicas?}

O reconhecimento de que as provas de larga escala e o Ideb subsidiariam a gestão de políticas públicas opôs, de um lado, os dois representantes do MEC e, do outro, os dirigentes da Campanha Nacional pelo Direito à Educação e da Comissão de Educação e Cultura da Câmara dos Deputados. Já o integrante do Conselho Nacional de Educação se colocou de forma neutra. Os argumentos dos primeiros se aproximam das ideias de Oliveira (2006), para quem uma indicação sistêmica de qualidade explicita as desigualdades existentes entre as escolas. Já os que se opõem associam-se às observações de Casassus (2007), segundo as 
quais os testes não possibilitam nada além da constatação da desigualdade, deixando de oferecer respostas que induzam a mudanças, tornando-se ineficaz dar aos testes em larga escala a legitimidade para articular as políticas educacionais.

O diretor de programas da Secretaria Executiva Adjunta do MEC, Arlindo Queiroz, considera que, apesar das limitações, o Ideb significa um avanço, na medida em que explicita as desigualdades educacionais encontradas no País, o que pode contribuir com a formulação e implementação de políticas de equidade. Na mesma linha, a secretária de Educação Básica do Ministério da Educação, Maria do Pilar Lacerda, referiu-se ao índice como um eficiente instrumento de política pública, na medida em que aponta os municípios mais carentes de apoio, assim como os que têm boas práticas a serem compartilhadas. "Você consegue organizar as políticas públicas através do mapa produzido pelos resultados do Ideb", disse ela.

Daniel Cara, da Campanha Nacional pelo Direito à Educação, disse que o potencial do Ideb de gerar mudanças nos sistemas de ensino é reduzido, pois o índice apenas constata uma situação, sem oferecer caminhos para a melhoria. "O desafio é constituir outras formas de avaliação que de fato deem respostas sobre o que precisa ser melhorado no sistema", afirmou.

César Callegari, do Conselho Nacional de Educação, considerou que as provas de larga escala são indicadores que propiciam a reflexão acerca das práticas escolares e das políticas públicas.

Para a deputada Maria do Rosário Nunes, alguns setores da sociedade confiam totalmente nas provas, acreditando que seus resultados e a classificação das escolas podem delinear um mapa da qualidade da educação, visão não compartilhada por ela.

\section{Interferência das provas no currículo?}

Outro ponto de divergência dos atores é a capacidade das provas de interferirem no currículo das escolas, o que se relaciona à existência e ao alcance do risco de as escolas reduzirem o ensino aos conteúdos monitorados pelos testes. Três posições puderam ser identificadas: a primeira, verificada no depoimento da coordenadora do Instituto Ayrton Senna, considera positiva e desejável a interferência no currículo, negando o efeito do risco, que se minimizaria diante da evolução do formato das provas; outra, presente no depoimento da oficial do Unicef, reconhece a existência do risco, mas relativiza seu alcance, considerando que os benefícios do uso das provas são maiores, apontando a definição de um currículo como um mecanismo para reduzir os efeitos indesejados; para a terceira posição, representada pela ANPEd e pela Campanha Nacional pelo Direito à Educação, as avaliações estariam criando uma dinâmica de treinamento dos estudantes para responderem aos testes, além de criar um ambiente de competição entre docentes e escolas. 
Segundo Tatiana Filgueiras, as provas usadas nos programas do Instituto Ayrton Senna - elaboradas com a matriz do Saeb - fazem parte de um contexto maior de organização e estruturação do dia a dia das escolas. As provas teriam o papel de orientar o ensino, estruturando as aulas em torno dos conteúdos avaliados, sendo encaradas como instrumentos de gestão das escolas. "Na verdade, as provas estruturam as ações pedagógicas e essas estruturam as provas" - disse ela.

Para Filgueiras, o risco de as escolas se concentrarem exclusivamente no ensino do que é monitorado nas avaliações é minimizado pela evolução das provas, que medem justamente o que se espera que os estudantes saibam: "A prova não nasce do nada, a prova nasce de uma expectativa do que as pessoas deveriam saber. [...] A prova deveria estar refletindo uma qualidade mínima que deveria estar garantida."

Maria de Salete Silva reconheceu o risco de as escolas concentrarem seus esforços nas respostas para as provas, alheando-se das demais aprendizagens necessárias: "Esses programas de avaliação têm que ter muito cuidado, para que não haja o risco de restringir o conteúdo ao que cai nas provas." Para superá-lo, a representante do Unicef propôs a definição de um currículo nacional comum: "O desafio agora é discutir o currículo, discutir o que a criança tem de aprender ano a ano."

Já para Sandra Zákia, da ANPEd, a influência nos currículos das escolas seria uma decorrência negativa da ênfase nas provas em larga escala como uma medida de qualidade. "Uma [das implicações práticas da ênfase nas provas] é condicionar o que é relevante em termos do currículo da escola" - disse.

O coordenador da Campanha Nacional pelo Direito à Educação, Daniel Cara, apontou o risco de o Ideb estimular a relação mecânica ensino-teste, relegando outros conteúdos fundamentais a um segundo plano: "Você prepara os alunos para as provas; desvirtua o processo."

Um ambiente de competitividade entre as escolas foi outro aspecto negativo levantado nos depoimentos em relação à maneira como as provas têm sido implementadas no Brasil. Essa foi a posição de Sandra Zákia, para quem a competitividade e a suposição de uma diferenciação entre os estabelecimentos seria uma implicação prática da ênfase nas provas e da produção de classificações de resultados.

\section{Prioridades para as políticas de magistério}

As prioridades para as políticas relacionadas ao magistério foi um dos pontos que mais provocaram discordância entre os atores. Alguns depoimentos se referiram ao grupo docente como uma questão-chave no debate da qualidade da educação. Contudo, se a convergência do tema pode ter formado um consenso, observa-se que os dissensos estariam situados nas formas priorizadas para garantir que o professorado cumpra com o papel que lhe é atribuído. 
O embate se dá principalmente em torno da remuneração. De um lado, os representantes da Campanha Nacional pelo Direito à Educação, do CNE e da CNTE argumentam que o aumento salarial é indispensável à qualidade da educação. De outro, os porta-vozes do Instituto Ayrton Senna e da Undime afirmam que os salários não são determinantes. Um terceiro grupo, expresso pela dirigente do MEC, reconhece a controvérsia, mas não se posiciona ante ela.

Entre os que defendem a centralidade dos salários predomina a compreensão de que este é um fator fundamental para atrair talentos ao magistério: melhorando-se os quadros de professores, melhoraria também o trabalho docente. Juntamente com as condições de trabalho e a formação continuada, a remuneração comporia a valorização profissional, entendida como imprescindível para a promoção da qualidade.

Os que acreditam que o salário não é central defendem que outros aspectos são mais importantes, como a dedicação e o engajamento do professor e a existência de um trabalho estruturado, que oriente a sua ação fundamentalmente para conquistar bons resultados no desempenho de estudantes nas avaliações centralizadas. A valorização do professor seria entendida principalmente como a garantia de apoio ao desenvolvimento de seu trabalho, isto é, formação continuada, disponibilização de materiais e apoio técnico para que se atinjam metas.

O tema do salário foi ainda polemizado com as propostas de bonificação por mérito. Entre os que defendem os bônus (de forma declarada, apenas a especialista do Banco Mundial se disse a favor), ${ }^{8}$ argumenta-se que funciona como um incentivo à dedicação e ao comprometimento dos professores com um ensino capaz de ser traduzido em um bom desempenho de estudantes. Os que se opõem (representantes da ANPEd, do CNE, da CNTE e do MEC) opinam que um sistema baseado em prêmios (e punições) não funciona, pois gera disputa e competição onde deve reinar solidariedade e cooperação. Outro argumento é o de que as propostas de bonificação por mérito partem de um entendimento que responsabiliza o professor pelo fracasso do desempenho dos alunos.

Segundo Daniel Cara, paradoxalmente, o ponto de maior consenso seria justamente o de maior dissenso quando o assunto é qualidade da educação. Para o coordenador da Campanha, se todos reconhecem a centralidade do professor na promoção da qualidade, as políticas relacionadas ao magistério são focos de divergência que se refletiriam na "corrente economicista" e na fundamentada na "perspectiva dos direitos"; o tema salarial seria um ponto de oposição dessas correntes. Para ele, "há quem acredite que o professor é central, mas que não precisa ganhar um salário justo. Buscam outras formas de resolver a centralidade do educador no processo educacional".

Roberto Leão se referiu aos salários sempre como parte da valorização profissional, que, por sua vez, comporia, juntamente com o investimento e a gestão democrática, o tripé defendido pela CNTE para "se atingir a educação pública de qualidade". Disse ele que "a valorização profissional
8 Entretanto, Madalena dos Santos afirmou que essa é uma opinião pessoal sua, não refletindo a posição oficial do Banco Mundial. 
não é só o salário; é salário, carreira, formação inicial muito consistente, formação continuada consistente e relacionada ao cotidiano do professor".

César Callegari mencionou a importância de trazer os melhores quadros profissionais para a sala de aula, quando discorreu sobre a aprovação das diretrizes nacionais da carreira e remuneração do magistério pelo CNE. Deduz-se que ele considere que o aspecto salarial é chave quando o assunto é qualidade da educação, embora ele não tenha sido assertivo.

Tatiana Filgueiras se posicionou claramente contra os que acreditam que o aumento salarial é uma das principais medidas a serem adotadas nas políticas direcionadas ao magistério. Para a coordenadora do Instituto Ayrton Senna, "o aumento de salário não necessariamente melhora a qualidade". Para Filgueiras, a melhoria da educação e do fluxo trará um excedente de recursos que pode ser revertido para os professores. "Acho que tem uma ordem para as coisas aparecerem, o aumento de salário não necessariamente melhora a qualidade, mas a melhoria da qualidade pode gerar recursos para o aumento dos salários", afirmou.

Carlos Eduardo Sanches, da Undime, falou sobre as pesquisas que indicam que a qualidade da educação (entendida como o resultado das provas centralizadas) não está relacionada ao nível salarial docente. O que de fato faria diferença seriam o engajamento e a competência do magistério: "Os melhores professores não são aqueles que ganham mais ou o que têm pós, mestrado e doutorado. Daí voltamos à estaca zero e vamos tratar do envolvimento, do engajamento, da dedicação e da competência de cada um."

Maria do Pilar Lacerda remeteu à divergência quanto à qualidade da educação relacionar-se ou não com o salário do magistério: "Muitas vezes a corporação dos professores faz essa discussão a partir do salário do professor, apesar de que eu avalie que as corporações tenham avançado neste debate. Mas ainda há um dissenso sobre se a qualidade passa pelo salário do professor." Lacerda não se posicionou em relação à polêmica, mas cabe a ressalva de que o MEC defende aumentos salariais (o piso nacional foi uma das medidas do Plano de Desenvolvimento da Educação).

Maria Lucia Reis, do Todos pela Educação, não deu opinião direta sobre o tema dos salários, mas destacou a importância de a carreira do magistério ser atrativa para a juventude.

Para Madalena dos Santos, o aumento salarial não seria uma solução promissora, pois nivela a profissão por baixo. A representante do Banco Mundial sugere que os professores sejam recompensados financeiramente segundo o desempenho de seus alunos, alimentando as discussões em torno das políticas de bonificação por mérito: "Ao dar aumento igual, independentemente dos resultados na sala de aula, estamos diminuindo a motivação do professor trabalhador."

Os métodos de punição e premiação dos profissionais da educação foram objeto do dissenso apontado por César Callegari. Ele afirmou que não defende que o professor seja punido ou até excluído da carreira 
docente em decorrência de resultados negativos da avaliação de seu trabalho, pois nunca viu o mecanismo funcionar.

As políticas de bonificação por resultado também foram abordadas por Roberto Leão. O presidente da CNTE questionou que a "qualidade do profissional", assim como sua motivação e estímulo, possa ser induzida pelos bônus. Para ele, as propostas subentendem que a responsabilidade pela qualidade da educação depende unicamente do professor: "É uma disputa que traz para dentro da escola um conceito de vida que está colocado hoje: o êxito ou o fracasso é responsabilidade unicamente do indivíduo."

Para Sandra Zákia, da ANPEd, as propostas de bonificação tenderiam a intensificar o ambiente de competição criado pela ênfase nas provas como uma medida de qualidade. A secretária de Educação Básica do MEC, Maria do Pilar Lacerda, também se posicionou contra as políticas de bonificação por mérito. "Eu não concordo com políticas que dizem que se o professor for punido a educação melhora, o que não quer dizer que eu defenda que o professor é um coitadinho."

Nos depoimentos, as posições em relação à importância dos salários e às políticas de bonificação foram acompanhadas de referências às maneiras de lidar com o magistério. Nesse sentido, Lacerda falou sobre a profissionalização: "Eu busco a profissionalização da educação, o professor é um profissional da educação, deve ser tratado como tal, então o piso salarial profissional é uma sinalização que o Ministério dá deste tratamento."

Para César Callegari, a "responsabilização pela assunção de níveis superiores de autonomia" é o caminho mais frutífero a ser adotado nas políticas para o magistério. "Quando as escolas são mais autônomas, mais empoderadas, professores, alunos e suas famílias tendem a assumir níveis maiores de responsabilidade e níveis maiores de desempenho", completou o integrante do CNE.

O apoio para o alcance de resultados foi colocado como central por Tatiana Filgueiras. "A valorização do professor é fundamental. Não é só aumentar salário, é ter credibilidade, ter condições de alcançar resultados, ser apoiado numa situação desafiadora", colocou a coordenadora do Instituto Ayrton Senna.

Para Daniel Cara, as apostas dos que defendem outras medidas que não os aumentos salariais se concentrariam em soluções relacionadas à gestão, como a adoção de apostilas, valorização moral e bonificação por resultados dos desempenhos dos alunos. Seu depoimento reflete uma divergência acerca do papel do magistério no processo educacional. Para ele, na corrente economicista, o professor seria basicamente treinado para dar aula, executando atividades e reduzindo sua autonomia e responsabilidade pelo processo pedagógico: "É uma busca por um caminho mais curto para chegar a uma educação de qualidade. Mas é um caminho errado. Com a apostilagem só se treina, não se forma professor. O professor não pensa estratégias pedagógicas, ele só executa." Segundo ele, esse modelo é atrativo por ser menos dispendioso: "E com esse modelo o gestor 
não precisa se preocupar com questões mais espinhosas, especialmente em termos orçamentários, como estruturar a carreira do magistério e aumentar salários."

Maria Lucia Reis, diretora do Todos pela Educação, destacou a relevância da formação e das condições de trabalho dos profissionais da educação: "A posição do professor na escola deve ser valorizada, com condições para ele dar aula, boas condições físicas da escola e alunos que tenham condições de aprender."

Madalena dos Santos se referiu à qualidade da formação docente como central. Para esta especialista do Banco Mundial, a oferta de vagas escolares para as classes mais desfavorecidas economicamente acompanhou uma mudança no perfil do magistério no País, o que se reflete na educação. Ela considera que a melhoria do trabalho docente depende da formação inicial, que precisa ser prática e focada no ensino, e da valorização do trabalhador, que não se resume ao salário, mas abrange também as condições de trabalho.

Santos falou sobre as dificuldades que permeiam as relações dos "gestores" com o magistério. Para ela, o sucesso de qualquer reforma educacional depende diretamente do investimento no professor: "Existe uma dificuldade das pessoas entenderem que, para fazer qualquer reforma, é preciso investir no professor. [...] Se o professor não é visto como parceiro na hora de se estabelecer uma reforma, [...] ela está fadada a fracassar."

\section{Conclusão}

Tendo como referência as preferências e as expectativas de resultados dos atores diante dos issues identificados, cabe-nos aplicar as ideias de Rua para a distinção do tipo de arena formada - distributiva, regulatória ou redistributiva -, assim como do padrão que rege a dinâmica das relações entre os atores - lutas, jogos ou debates. Porém, antes de tomar esse caminho, é prudente apontar os limites estabelecidos pela pesquisa e considerar que temos apenas indícios para efetuar as distinções mencionadas. A opção de trabalhar com os discursos dos atores pode levar a armadilhas semânticas, incapazes de revelar as nuanças que se desvelam no nível das ações, de forma que o resultado da pesquisa contribui com elementos de análise da temática em questão.

A paisagem da pesquisa não descortina uma arena altamente conflituosa. Existem divergências de concepções e opiniões, que induzem a ações e horizontes distintos, mas, segundo as ações citadas pelos entrevistados, não ocorre um confronto direto entre os atores, entendido como um enfrentamento de forças que competem num mesmo espaço. Com exceção da CNTE, os entrevistados não mencionaram oponentes ou focos de dissenso que inviabilizem a formação de alianças. Os atores divergem, opõem-se entre si, principalmente em torno dos três issues mencionados, mas não declaram guerra um ao outro. Por isso, não se 
determina uma arena redistributiva, caracterizada por ser altamente conflituosa.

Um fato importante é a própria relação entre os vários atores. A CNTE e a Undime fazem parte da diretoria da Campanha Nacional pelo Direito à Educação. A Undime também integra o movimento Todos pela Educação e é parceira do Unicef e do MEC em várias ações, como a produção de publicações e a realização de encontros de dirigentes educacionais dos municípios. Além da Undime, o MEC tem parcerias com o Unicef e o Banco Mundial e grande interlocução com a Campanha e o Todos pela Educação (as duas organizações tiveram influência no desenho do PDE). O Conselho Nacional de Educação tem seus membros nomeados pelo ministro da Educação, e o vice-presidente da Câmara de Educação Básica é o diretorexecutivo do Todos pela Educação. O Instituto Ayrton Senna é membro dessa última instituição. A Comissão de Educação e Cultura da Câmara dos Deputados, apesar de mais independente, mantém relações com todos eles, tendo chamado, por exemplo, representantes da Campanha e do Todos pela Educação para participar de audiências ao longo do ano de 2009. A ANPEd, também de viés independente, já participou de grupos técnicos para desenho de programas do MEC. Enfim, um emaranhado de relações de colaboração.

Os depoimentos também não comprovam que se trata de uma arena distributiva - aquela que mobiliza reduzido potencial de conflito -, pois há conflitos nos issues mencionados. Dependendo das decisões tomadas, atores ganham e atores perdem segundo suas preferências.

Ao que tudo indica, constitui-se uma arena regulatória, que trata da alocação de recursos e da distribuição de benefícios. Um ponto essencial a ser destacado nessa interpretação é o de que, se na composição da arena buscamos selecionar atores com vinculações sociais distintas, que pudessem representar interesses diferentes em jogo no campo educacional, observamos ao final que os atores falam em nome de grupos sociais com os quais têm fraca vinculação. A maior parte diz expressar o interesse não dos grupos que representam: numa linguagem vaga, falam em nome do Brasil, da educação, dos direitos da criança e do adolescente (ou dos "alunos"). Ao defender o aumento de salários para o magistério, a assunção de metas educacionais, a adoção de ferramentas de gestão, a definição de indicadores nacionais que organizem as políticas públicas, a importância das condições para a promoção da qualidade, todo um rol de procedimentos é desvelado em nome dos direitos de estudantes a uma "educação de qualidade". Ou seja, trata-se de atores frágeis em termos de serem representantes de grupos sociais definidos. Politicamente, os atores podem perder quando sua proposta não é inteiramente adotada, mas, em termos sociais, essa perda não é tão clara. Os atores se confrontam menos como atores sociais e mais como atores políticos; a lógica do sistema político predomina sobre a lógica dos atores sociais.

Quanto ao padrão que rege a dinâmica das relações entre os atores, a pesquisa indica que sejam os jogos - "situações em que a lógica é vencer o adversário em uma situação específica, sem eliminá-lo totalmente do 
processo, de tal maneira que ele possa vir a ser um aliado em um momento posterior" (Rua, 1998b, p. 241-242). Há um entrelaçamento de relações entre os atores, que celebram alianças e se opõem em torno dos issues. Os atores divergem entre si, mas não se engajam em ações de confronto em nome das divergências.

Tendo como referência os depoimentos tomados, o que está em jogo nas noções de qualidade da educação para alguns dos principais atores sociais do campo educacional é a redução das desigualdades educacionais, vista por dois prismas distintos: 1) a elevação do desempenho dos estudantes nas provas de larga escala; e 2) a garantia de condições variadas de ensino que conduzam a uma formação ampla dos estudantes, abrangendo não só os conteúdos curriculares, como também a cidadania e capacidades éticas.

Todos convergem ao defender uma educação que de fato proporcione boa formação a estudantes, orientada para o desenvolvimento significativo de cada pessoa e da sociedade como um todo e combatendo uma escolarização que passe "em branco" na vida das crianças e adolescentes. Para uns, isso se traduz em garantir aprendizagem capaz de ser medida pelas provas padronizadas; para outros, em priorizar processos, condições e uma aprendizagem mais ampla, que envolve os "conteúdos" disciplinares e a cidadania.

\section{Referências bibliográficas}

ADAMS, D. Defining educational quality. Arlington: Institute for International Research, 1993. 18 p.

CAMPOS, M. M. Que qualidade buscamos na América Latina? In: CAMPANHA NACIONAL PELO DIREITO À EDUCAÇÃO. A educação na América Latina: direito em risco. São Paulo: Campanha Nacional pelo Direito à Educação, Cortez, 2006. p. 23-27.

CARVALHO, J. S. F. "Democratização do ensino" revisitado. Educação e Pesquisa, São Paulo, v. 30, n. 2, p. 327-334, maio/ago. 2004.

CASASSUS, J. Evaluación educativa, segmentación social y pérdida de calidad. In: SIMPÓSIO BRASILEIRO DE POLÍTICA E ADMINISTRAÇÃO DA EDUCAÇÃO, 23, 2007, Porto Alegre. Por uma escola de qualidade para todos: programação e trabalhos completos. Porto Alegre: Anpae, 2007. (Série Cadernos Anpae, n. 4).

OLIVEIRA, R. P. Estado e política educacional no Brasil: desafios do século XXI. 2006. Tese (Livre-docência) - Faculdade de Educação, Universidade de São Paulo, 2006. 
RUA, M. G. As políticas públicas e a juventude dos anos 90. In: CNPD. Jovens acontecendo na trilha das políticas públicas. Brasília: CNPD, 1998a. p. 731-749.

RUA, M. G. Análise de políticas públicas: conceitos básicos. In: RUA, M. G. ; CARVALHO, M. I. V. de. O estudo da política: tópicos selecionados. Brasília: Paralelo 15, 1998b. p. 231-260.

TORRES, R. M. Educação para Todos: a tarefa por fazer. Trad. Daisy Vaz de Moraes. Porto Alegre: Artmed, 2001. 104 p.

Joana Buarque de Gusmão, mestre em Educação pela Faculdade de Educação da Universidade de São Paulo (FE-USP), atua como pesquisadora e consultora em educação.

joanabg@uol.com.br

Recebido em 23 de novembro de 2011.

Aprovado em 7 de novembro de 2012. 